\title{
Plastics in the hydrosphere
}

\section{Jessica Hickie and Fiona Tovey report on an urgent problem requiring global action}

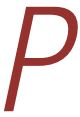

lastic pollution is recognised as one of the most serious problems facing our planet. Global production, use and ultimately disposal of plastics continues to soar, posing an increasing threat to our environment. There is an urgent need for global action, backed by sound scientific understanding. With these issues in mind, the Environment Agency convened a session at the European Geosciences Union (EGU) in April 2019 (https:// meetingorganizer.copernicus.org/ EGU2019/session/30244). The aim was to bring to the attention of some of the 16,000 scientists and policy makers in attendance, the need to focus more research on the impact of plastics on our land, rivers and oceans.

Research on plastic, until recently, has mostly centred on the marine environment, and this was reflected in the conference session, with the initial talks largely discussing the oceans. However, a key point that came from the session is the need to focus research upstream. As Jo Ruxton, a film director, put it "The ocean is the final casualty, but the rivers are like the arteries that feed it". We must investigate the sources, pathways and effects of plastics on their journey to the sea. And we can't approach the problem from a purely physical science perspective.
The plastics crisis is also a social problem and it is essential that geoscientists engage with those in various sectors, including social scientists, those working in industry, policy makers, campaigners and the public, to create positive behaviour change.

Six speakers-most of whom were not geoscientists - each brought a unique perspective to the session, and together helped to tell the whole story of plastics and us-a story that influences on a global scale.

\section{Where is all the plastic?}

The main problem with plastic is that it was designed not to disappear, which is why it breaks up and not down, and persists in the natural world as microplastics. As emphasised by Jo Ruxton, we know that plastic production is increasing. In the 1950s and 60s, we were producing less plastic globally than what enters the oceans now. So, where is it all going?

Dr Erik van Sebille (Utrecht University, Netherlands), an oceanographer and climate scientist, investigates the time scales and pathways of the global ocean circulation. He told us that plastic is now found everywhere-in the water column, ocean floor, sediment and in organisms. However, currently we can only account for $1 \%$ of the plastic that we know is in our environment. So where is the missing $99 \%$ ? Two pieces of plastic that start close together can end up hundreds of miles apart, so at some point you have no idea where the plastic has been.

Numerical models and simulations help us create maps to estimate how much plastic is floating around in the ocean, where it is floating and where it congregates. High concentrations are found in South East Asia, the Mediterranean and the mid-latitude areas called "garbage patches". However, it is not enough to know where the plastic is; we need to know where the animals and interactions with plastic are.

By combining the maps of plastic distribution with those of where seabirds feed, we are able to identify the locations where seabirds are most at risk. And this turns out to be the Southern Ocean. The same approach can be used for other animals, such as turtles, where the risk of plastic ingestion is highest in their foraging locations, mostly relatively close to shore.

Erik emphasised that we need to "Be careful not to make plastic the enemy. If we 
go too far then it can be detrimental to the environment." That is, environmental risk stems not just from how much plastic there is, but from where it is distributed. Only by establishing this risk can we truly understand the ecological impacts.

\section{Turning the tide}

While research into plastic distribution continues, we should remember that the 'plastic problem' has only become a focus for the public relatively recently. Jo Ruxton began her journey into plastics following a career with the BBC, working with Sir David Attenborough on series such as Blue Planet. Jo noticed that they tended to film the beauty of the natural world and not the negatives, such as plastic pollution, and felt the need to show the world, through film, what impact our addiction to plastic was having on the oceans. Over eight years, Jo produced the multi-award-winning film, A Plastic Ocean (see page 10).

Jo talked about the challenge of finding funding for the film because, at the time, few people believed the topic would be of general interest. However, her passion drove her on and the film, which shows strong images of birds with stomachs full of plastics, as well as island nations devastated by single-use plastics, has had a major impact.
Jo is also now full of hope for the next generation, having witnessed inspirational changes in behaviour from children while visiting their schools.

Indeed, the tide has now turned. As Hugo Tagholm (Chief Executive of the charity Surfers Against Sewage) pointed out, of the seven hours of Blue Planet II documentary, only 14 minutes was dedicated to plastic pollution, yet this changed how government, industry, NGOs and individuals responded to plastics in a way that has never been seen before.

For example, Surfers Against Sewage mobilises over 75,000 beach clean volunteers annually and works closely with government and industry to reduce plastic pollution. Their most successful initiative, Plastic Free

Communities, brings together businesses, the public and schools to tackle plastic pollution. Within two years of launch, there were 500 communities representing 30 million people, from Hackney in London to the Highlands in Scotland. The charity's projects demonstrate how environmental issues can

be tackled by individuals working together.

\section{Personal connection}

This intense public response to plastics is largely due to people being able to see and connect with the problem. As a poignant example of this, Lucy Siegle, an independent writer and journalist who specialises in communicating Earth science and telling environmental narratives, projected onto the conference screen a photograph of a shrink-wrapped coconut. The image of single-use plastic replacing a perfectly natural outer skin instantly highlighted our unnecessary and excessive use of this material. Lucy explained that "We have to have a diverse way of telling the story so people will connect". People react to things differently because they have different cognition and cultural experiences or fears, so they express things in a very different way. That is, as scientists, we must socialise our science.

The importance of a personal connection was stressed by Hanli Prinsloo, founder of the I AM WATER foundation, which focuses on ocean conservation through human experience. The competitive free diver pushed the audience to connect with ocean health on a personal level by asking them to take several deep breaths together. In thinking about why we should care how well our oceans are doing, Hanli told us that more than $50 \%$ of oxygen in our atmosphere comes from the ocean, so at least every second breath we take is thanks to the ocean. And Hanli emphasised that it's not just that our survival depends on the ocean. What would we be if we didn't protect this great wilderness? What does it say about us as a species if we 
cannot take care of $70 \%$ of our planet? Our bodies are about $70 \%$ water, so there is a great connection!

Hanli feels that we are given the opportunity to share our environment with so many species, yet we are not being very good friends at this time: "It is not a human planet, it is a shared planet. It is arrogant to call us the custodians of it". This sentiment was echoed by Hugo Tagholm: "We can't knowingly carry on creating plastic whilst our animals carry on suffering and dying". Hanli stressed the intelligence of the creatures we share this planet with, saying that if there's one thing that makes humans unique, it is that we have choices and our choices matter. This blue is truly our last wilderness and there is so much left to fight for.

Addressing the scientific audience in front of her, Hanli urged us to communicate not just the facts and statistics, but the need to care. Only then will we see true behavioural change-a change for the oceans and the good of ourselves.

\section{Giving plastic new life}

Following intense media coverage, plastics are now firmly on the agenda. But, what's next? The 'plastics problem' is not simply an environmental issue. As Ed Mitchell (Director of Environment \& Sustainability at Pennon Group Plc. and Wastewater Operations Director at South West Water) put it, "We have a legal and moral responsibility to protect our environment. Society and the economy rely on it." He reminded the audience that plastic is an incredible resource to be valued in a circular economy.

Ed told us that businesses are starting to see plastic as a resource, rather than waste, through innovation. By using recycled plastic, manufacturers can reduce the need to create virgin polymers from oil, saving $\mathrm{CO}_{2}$ and energy. Substituting a tonne of virgin polypropylene (PP), such as that used in yoghurt pots, with recycled PP would save nearly $1,200 \mathrm{~kg}$ of $\mathrm{CO}_{2}$-equivalent to driving the material from London to Milan in a standard lorry.

Ed also explained Government's influence in changing our approach to plastics. In 2018, the UK Government announced it is considering introducing a new tax on the production and import of plastic packaging with less than $30 \%$ recycled content. This creates an incentive for companies like the Pennon Group to invest in new recycling

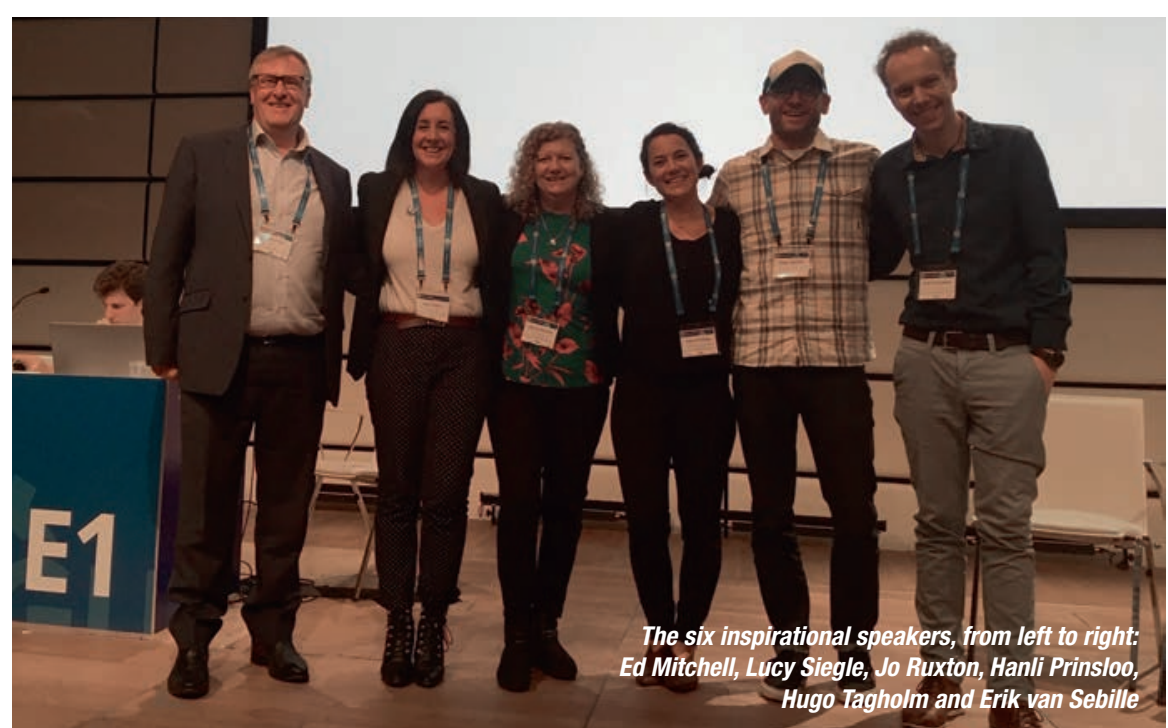

infrastructure in the UK, therefore reducing the export of plastics.

The 'plastics problem' is caused by too much of the wrong waste in the wrong place. Ed feels that the focus needs to be on removing unnecessary and poorly designed packaging and products, alongside boosting investment in recycling.

\section{Barrier or gateway?}

Some have questioned whether the recent intense focus on plastics is drawing attention away from other important environmental issues, such as climate change. However, Lucy Siegle, who hosted a weekly segment on BBC1 dedicated to turning the tide on plastic, highlighted that plastic is also a very important touch stone for people who are not ready to talk about climate change, linked through carbon.

Carbon emissions from the plastics industry are vast and growing. Currently, $6 \%$ of global oil demand fuels plastic production, but by 2050 (as other parts of the economy decarbonise) plastics may well be responsible for $15 \%$ of all greenhouse gas emissions. So, the 'plastics problem' provides an opportunity to educate people on less obvious carbon footprints associated with human activity.

\section{System change}

The conference session was incredibly well attended-over 1,000 delegates witnessed the four-hour session. The speakers were inspirational and completely engaged an audience of geoscientists who perhaps had not considered playing a part in solving the plastics crisis.

Dr David Todd at HR Wallingford commented, "It was incredible to see such a big venue at standing room only-an exceptional achievement-filled with some of the world's leading geoscientists, who witnessed a set of incredible, inspiring, moving talks on plastic waste-what it is, what it means, and what we can do about it. Such brilliant speakers could not fail to move an audience to action."

There is not an easy solution to the plastic crisis we have created. Many people and organisations are doing lots of great things, but to really make a difference requires system change. The whole industry must work together-from the creation of new materials and thinking about a product's 'end of life' at the 'beginning of life', through to manufacturing, marketing, consumer disposal, collection, facilities, policies and legislation.

Geoscientists have an important role to play in this collaboration. In addition to carrying out research to fill in any gaps in understanding or evidence, we must also work with government and business to communicate our science in a way that all audiences understand. Only by working across disciplinary boundaries can we bring about sustainable change for the good of all life on Earth.

Jessica Hickie, Programme Manager for the Environment Agency's Plastics and Sustainability Team

Fiona Tovey, Project Manager for the Environment Agency's Plastics and Sustainability Team 